\title{
Efficient Cryopreservation of Lilium spp. Shoot Tips using Droplet-vitrification
}

\author{
Jung Yoon Yi ${ }^{1 *}$, Gi An Lee ${ }^{1}$, Jong Wook Chung ${ }^{1}$, Sok Young Lee ${ }^{1}$, and Ki Byung Lim ${ }^{2}$ \\ ${ }^{1}$ National Agrobiodiversity Center, NAAS, RDA, Suwon, 441-853, Korea \\ ${ }^{2}$ Dep. of Horticultural Sciences, Kyungpook National University, Daegu, 702-701, Korea
}

\begin{abstract}
Newly developed shoot tips from adventitious buds induced by tissue cultured bulb-scale segments of five accessions of Lilium spp. were successfully cryopreserved by a droplet-vitrification method. Bulb-scale segments cultured on Murashige and Skoog (MS) medium with $0.1 \mathrm{mg} \cdot \mathrm{L}^{-1}$ IAA and $0.1 \mathrm{mg} \cdot \mathrm{L}^{-1}$ zeatin were then cold-hardened at $4{ }^{\circ} \mathrm{C}$ for 7 days. The excised shoot tips were pre-cultured on solidified MS medium containing $0.3 \mathrm{M}$ sucrose for 1 day at $23^{\circ} \mathrm{C}$ and then soaked in a mixture of $0.7 \mathrm{M}$ sucrose for a day at $23{ }^{\circ} \mathrm{C}$. Pre-cultured shoot tips were cryoprotected with two loading solutions, LD1 and LD2, which included $35 \%$ and $40 \%$ plant vitrification solution (PVS3), respectively, for $40 \sim 60 \mathrm{~min}$ at $23{ }^{\circ} \mathrm{C}$. The cryoprotected shoot tips were then soaked in PVS2, modified PVS2 and PVS3 for $90 \sim 120 \mathrm{~min}$ at $23^{\circ} \mathrm{C}$. The shoot tips, frozen in microdroplets of vitrification solution, were wrapped with aluminum foil strips, which were immersed rapidly in liquid nitrogen. The shoot tips were then rapidly warmed using unloading solution, transferred to a regeneration medium, stored in the dark for two weeks at $23{ }^{\circ} \mathrm{C}$, and then cultured under white fluorescent light at an intensity of 2000 lux with a 16 -h photoperiod at $23^{\circ} \mathrm{C}$. The average post-cryo regeneration rates of five accessions ranged from $52.7 \%$ to $87.5 \%$.
\end{abstract}

Keywords Cryopreservation, Droplet-vitrification, Lilium, Vitrification, Shoot-tips

\section{INTRODUCTION}

The genus Lilium comprises about 100 species distributed in the northern hemisphere and extending through to the Asian tropics (latitude $10 \sim 60^{\circ}$ ). In Korea, 15 species of lily have been reported, but their exact number varies on the researchers (Lee 2002).

As with other plant species, Lilium are also facing the threat of genetic erosion, therefore increasing attention is being paid on the conservation of Lilium germplasm. This is because the genus Lilium represents one of the most important crops of cut flowers and pot plants worldwide, and it is also used as a vegetable and medicine in some parts of the world.

The germplasm resources of lily cannot be preserved in low-temperature seed banks because they are vegetatively propagated. Furthermore, in vivo field preservation is labor intensive, and there is considerable risk of loss due to disease or extreme weather. Additionally, in vitro tissue culture conservation is susceptible to contamination and somaclonal variation. Thus, cryopreservation of the lily meristem or shoot tip may represent a suitable method for long-term preservation. Several research results have indicated that the meristems of lily have been cryopreserved successfully using techniques of vitrification (Bouman and De Klerk 1990). Other researchers have reported that lilies have been cryopreserved by vitrification and encapsulationdehydration (Bouman et al. 2003; Chen et al. 2007; Matsumoto et al. 1995; Zhang et al. 2004; Kaviani et al. 2008). Chen et al (2011) reported the first successful cryopreservation of Lilium spp. by droplet-vitrification using meristems from adventitious buds. Droplet-vitrification combines droplet freezing with vitrification protocols and is a very efficient cryopreservation method (Kim et al. 2006; Yoon JW et al. 2006).

Received Jun 14, 2013; Revised Jun 19, 2013; Accepted Jun 19, 2013; Published June 30, 2013

*Corresponding author JungYoon Yi, naaeskr@korea.kr, Tel: +82-31-299-1886, Fax: +82-31-299-1839 
In this study, to improve the droplet-vitrification cryopreservation method for lily shoot tips, we tested two kinds of loading solution and three types of dehydration solutions on five Lilium spp. germplasms. We determined the most efficient loading solution and the optimum application time, after which we tested three types of dehydration solutions and treatment times.

\section{MATERIALS AND METHODS}

\section{Preparation of plant material}

The basal medium used for all the trials was Murashige and Skoog (MS) containing 3\% sucrose and adjusted to a $\mathrm{pH}$ of 5.8 prior to autoclaving at $121^{\circ} \mathrm{C}$ for $15 \mathrm{~min}$. Adventitious buds were formed on the surface of bulbscale segments after 30 days on MS medium with 0.1 $\mathrm{mg} \cdot \mathrm{L}^{-1}$ indole-3-acetic acid (IAA), $0.1 \mathrm{mg} \cdot \mathrm{L}^{-1}$ zeatin, $3 \%$ sucrose, and $2.2 \mathrm{~g} \cdot \mathrm{L}^{-1}$ phytagel. Bulb-scale segments were sub-cultured to conserve or multiply on MS medium with $0.15 \mathrm{mg} \cdot \mathrm{L}^{-1}$ IAA, $0.2 \mathrm{mg} \cdot \mathrm{L}^{-1}$ zeatin, $1 \mathrm{~g} \cdot \mathrm{L}^{-1}$ charcoal, 30 $\mathrm{g} \cdot \mathrm{L}^{-1}$ sucrose, and $2.7 \mathrm{~g} \cdot \mathrm{L}^{-1}$ phytagel. For forming in vitro bulb, we used MS medium with $0.15 \mathrm{mg} \cdot \mathrm{L}^{-1}$ IAA, 0.2 $\mathrm{mg} \cdot \mathrm{L}^{-1}$ zeatin, $1 \mathrm{~g} \cdot \mathrm{L}^{-1}$ charcoal, $7.5 \%$ sucrose, and $2.7 \mathrm{~g} \cdot \mathrm{L}^{-1}$ phytagel. All the cultures were carried out under white fluorescent light (2000 lux) with a 16-h day photoperiod at $23^{\circ} \mathrm{C}$.

\section{Cold hardening and pre-culture}

Bulb-scales cultured on MS medium with $0.1 \mathrm{mg} \cdot \mathrm{L}^{-1}$ IAA, $0.1 \mathrm{mg} \cdot \mathrm{L}^{-1}$ zeatin, $3 \%$ sucrose, and $2.2 \mathrm{~g} \cdot \mathrm{L}^{-1}$ phytagel at $23^{\circ} \mathrm{C}$ for 2 weeks were cold-hardened at $4^{\circ} \mathrm{C}$ for 7 days under white fluorescent light (2000 lux) with a 16-h day photoperiod at $23^{\circ} \mathrm{C}$. The apical shoot tips were precultured in liquid MS basal medium supplemented with 0.3 $\mathrm{M}$ sucrose overnight. They were then placed in $0.7 \mathrm{M}$ sucrose overnight under the same light conditions as indicated previously.

\section{Loading and dehydration procedure}

Pre-cultured shoot tips were osmoprotected in loading solution for 40 and $60 \mathrm{~min}$ at $23^{\circ} \mathrm{C}$. The loading solutions, designated LD1 and LD2, contained MS basal medium supplemented with $35 \%$ and $40 \%$ plant vitrification solution 3 (PVS3), respectively (Table 1). The shoot tips were then soaked in three types of vitrification solution: PVS2, modified PVS2, and PVS3, for 90 360 min. For the droplet-vitrification treatment, five shoot tips were transferred to one droplet of vitrification solution on thin strips of sterile aluminum foil. The aluminum foil strips were then carefully immersed into liquid nitrogen using fine forceps. After immersion, the strips were quickly transferred to $2 \mathrm{~mL}$ cryotubes, which were immediately plunged into liquid nitrogen.

\section{Thawing and plant regeneration}

Samples were maintained in liquid nitrogen for at least 1 day. For warming, foil strips were taken out of the cryovials and immediately plunged into a pre-heated $\left(40^{\circ} \mathrm{C}\right)$ unloading solution containing $0.8 \mathrm{M}$ sucrose for $30 \mathrm{~s}$, after which another $5 \mathrm{~mL}$ of room temperature unloading solution was added. The shoot tips were then incubated at room temperature for $30 \mathrm{~min}$ to facilitate unloading. This step helps to rinse the highly concentrated vitrification solution from shoot tips. After thawing and unloading, shoot tips were placed onto regeneration medium containing MS

Table 1. Compositions of the vitrification and loading solutions used in this study.

\begin{tabular}{ccc}
\hline \hline Solution & Composition & Reference \\
\hline PVS2 & $30 \% \mathrm{G}^{\mathrm{z}}+15 \% \mathrm{DMSO}^{\mathrm{y})}+15 \% \mathrm{EG}^{\mathrm{x}}+13.7 \% \mathrm{Suc}^{\mathrm{w})}$ in MS & Sakai et al. 1990 \\
Modified PVS2 & $37.5 \% \mathrm{G}+15 \% \mathrm{DMSO}+15 \% \mathrm{EG}+22.5 \% \mathrm{Suc}$ in MS & - \\
PVS3 & $50 \% \mathrm{G}+50 \% \mathrm{Suc}$ in MS & Nishizawa et al. 1993 \\
LD1 & $35 \%$ of PVS3 & \\
LD2 & $40 \%$ of PVS3 & \\
\hline
\end{tabular}

${ }^{\text {z) }}$ G, glycerol; ${ }^{\text {y) }}$ DMSO, dimethyl sulfoxide; ${ }^{\text {x) }}$ EG, ethylene glycol; ${ }^{\text {w) }}$ Suc, sucrose 

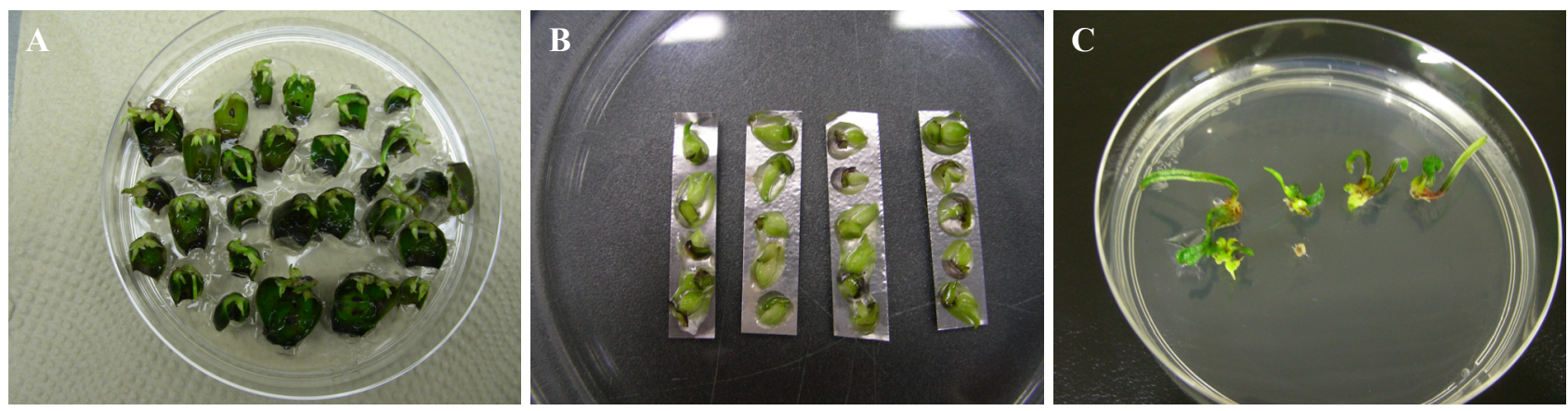

Fig. 1. Cryopreservation of lily shoot tips using droplet-vitrification. A) bulb-scale culture for producing shoot tips for cryopreservation; B) dehydration of shoot tips in vitrification solution droplets on aluminum foil strips; and C) plant regeneration from cryopreserved shoot tips 2 weeks after cryopreservation.

supplemented with $0.15 \mathrm{mg} \cdot \mathrm{L}^{-1} \mathrm{IAA}, 0.2 \mathrm{mg} \cdot \mathrm{L}^{-1}$ zeatin, 0.05 $\mathrm{mg} \cdot \mathrm{L}^{-1} \mathrm{GA}_{3}, 15 \mathrm{mg} \cdot \mathrm{L}^{-1}$ putrascine, $30 \mathrm{~g} \cdot \mathrm{L}^{-1}$ sucrose, and 2.2 $\mathrm{g} \cdot \mathrm{L}^{-1}$ phytagel and cultured in the dark for 2 weeks at $23^{\circ} \mathrm{C}$. They were then cultured under white fluorescent light at an intensity of 2000 lux with a 16 -h photoperiod at $23^{\circ} \mathrm{C}$.

\section{Assessment of survival and regeneration rates}

Survival rates were evaluated 14 days after cryopreservation by counting the number of shoot tips that were green and swollen ( $>3 \mathrm{~mm}$ ). Approximately 18 to 20 shoot tips were used per treatment, and each experiment was replicated three times. Regeneration rates were estimated at 7 to 8 weeks after cryopreservation by counting the number of shoot tips that were differentially swollen and green.

\section{Data analysis and statistical procedures}

The results were obtained as average percentages with standard deviations. Each experiment consisted of three replicates per treatment, and each cryovial held 10 samples. The results were analyzed by ANOVA, and the means were separated using Duncan's multiple-range test $(\mathrm{p}<0.05)$

\section{RESULTS AND DISCUSSION}

\section{Effects of cold hardening}

Table 2 showed the effects of cold hardening on the survival and regeneration rates of cryopreserved lily germplasms. In all five accessions, the survival and regeneration rates of cold-hardened shoot tips were considerably higher than those of controls, implying a requirement of cold hardening for the cryopreservation of shoot tips in Lilium spp. Cold hardening of donor plants tends to induce an intrinsic tolerance to low temperature and desiccation by triggering genes responsible for cold stress (Takagi 2000). Tahtamouni and Shibli (1999) demonstrated that cold hardening of the mother stock for 3 weeks at $4{ }^{\circ} \mathrm{C}$ under dark conditions followed by vitrification treatment improved the survival and re-growth of cryopreserved shoot tips of wild pear. When the shoot tips of strawberry were cryopreserved by encapsulation-vitrification, those shoot tips that were cold-hardened at $4^{\circ} \mathrm{C}$ for 2 weeks showed higher levels of shoot formation when compared with nonhardened shoot tips (Hirai et al. 1998).

Table 2. Effect of cold-hardening on the survival and regeneration percentage of shoot tips of the five accessions of Lilium spp.

\begin{tabular}{ccccccc}
\hline \hline & & \multicolumn{5}{c}{ Accession No. } \\
\hline & & GBL0089 & GBL0099 & GBL0202 & GBL0474 & GBL0518 \\
\hline $\begin{array}{c}\text { Survival rate } \\
(\%)\end{array}$ & Cold-hardened & $89.5 \pm 5.83^{\text {z) }}$ & $67.9 \pm 5.31$ & $83.3 \pm 4.33$ & $57.7 \pm 3.67$ & $67.9 \pm 4.87$ \\
& Control & $43.3 \pm 2.21$ & $31.3 \pm 2.87$ & $43.3 \pm 1.22$ & $24.3 \pm 1.13$ & $40.2 \pm 3.25$ \\
\hline $\begin{array}{c}\text { Regeneration } \\
\text { rate(\%) }\end{array}$ & Cold-hardned & $87.5 \pm 3.32$ & $64.3 \pm 4.34$ & $77.8 \pm 2.41$ & $52.7 \pm 2.83$ & $60.7 \pm 4.63$ \\
\hline
\end{tabular}

${ }^{\text {z) }}$ Mean \pm standard deviation 


\section{Effects of loading solution and application time}

Pre-cultured shoot tips were osmoprotected with a mixture of glycerol and sucrose. Many papers have reported that osmotic loading treatment (or loading treatment) increases the osmotic level of the cell and minimizes osmotic damage caused by the vitrification solution (Volk et al. 2004). The effects of loading solution and application time on the survival and shoot formation rates of vitrified shoot tips are summarized in Table 3. Two types of loading solutions tested were both very effective at improving the survival and regeneration rates of vitrified shoot tips cooled to $-196^{\circ} \mathrm{C}$.

As shown in Table 3, the highest survival (89.5\%) and regeneration rates $(87.5 \%)$ occurred with the treatment with LD1 for $60 \mathrm{~min}$. Thus, LD1 treatment for $60 \mathrm{~min}$ is considered optimal in the osmoprotectant solution to achieve plant survival and regeneration after cryopreservation. In the paper by Matsumoto et al (1994), a mixture of $2 \mathrm{M}$ glycerol plus $0.4 \mathrm{M}$ sucrose provided the highest rate of shoot formation in wasabi meristems. Therefore, a mixture of $2 \mathrm{M}$ glycerol plus $0.4 \mathrm{M}$ sucrose was adopted as the loading solution for Lilium spp. meristems in subsequent experiments. The selection of cryoprotectant is one of the most important factors for successful cryopreservation, because osmopretection before vitrification is based on the ability of highly concentrated cryoprotectant solutions to function without causing plant injury (Rall and Fahy 1985; Benson et al. 1996).

\section{Effects of vitrification solution and application time on recovery}

To determine the optimal vitrification solution and application time, pre-cultured and loaded shoot tips were dehydrated using PVS2, modified PVS2 and PVS3 for 90 360 min prior to a plunge into liquid nitrogen (LN). The highest rate of shoot formation was obtained from shoot tips treated with PVS3 for $240 \mathrm{~min}$ at $23^{\circ} \mathrm{C}$ (Table 4). Shoot tips treated with PVS2, modified PVS2, and PVS3 for 90 360 min at $23^{\circ} \mathrm{C}$ without cooling in $\mathrm{LN}$ (treated control)

Table 3. The effect of different loading solutions and treatment times on the survival and regeneration rates of the control (-LN) and cryopreserved $(+\mathrm{LN})$ lily shoot tips of the Lilium hybrid Carmina.

\begin{tabular}{ccccc}
\hline \hline Loading solution & \multicolumn{2}{c}{-LN } & \multicolumn{2}{c}{+ LN } \\
\hline & Survival (\%) & Regeneration (\%) & Survival (\%) & Regeneration (\%) \\
\hline Non-loading & 98.3 & 97.3 & $45.3 \mathrm{~d}^{\mathrm{z})}$ & $38.3 \mathrm{~d}$ \\
LD1 40 $\mathrm{min}$ & 99.3 & 97.8 & $80.3 \mathrm{a}$ & $78.5 \mathrm{ab}$ \\
LD1 60 $\mathrm{min}$ & 98.2 & 97.7 & $89.5 \mathrm{a}$ & $87.5 \mathrm{a}$ \\
LD2 40 $\mathrm{min}$ & 97.9 & 96.9 & $66.3 \mathrm{~b}$ & $63.5 \mathrm{~b}$ \\
LD2 60 $\mathrm{min}$ & 99.1 & 98.3 & $53.2 \mathrm{c}$ & $50.3 \mathrm{bc}$ \\
\hline
\end{tabular}

${ }^{z)}$ Mean separation within columns by Duncan's multiple range test at 5\% level

Table 4. The effect of different vitrification solutions and treatment times on the survival and regeneration rates of the control $(-\mathrm{LN})$ and the cryopreserved $(+\mathrm{LN})$ shoot tips of the Lilium hybrid Carmina.

\begin{tabular}{ccccc}
\hline \hline $\begin{array}{c}\text { Vitrification solution } \\
\text { \& time }\end{array}$ & \multicolumn{2}{c}{-LN } & \multicolumn{2}{c}{+ LN } \\
\hline PVS2 90 min & 99.9 & Regeneration (\%) & Survival (\%) & Regeneration (\%) \\
\hline Modified PVS2 90 min & 97.1 & 95.3 & $25.5 \mathrm{c}$ & $18.3 \mathrm{~d}$ \\
Modified PVS2 150 min & 95.3 & 96.9 & $49.8 \mathrm{bc}$ & $32.3 \mathrm{c}$ \\
PVS3 180 min & 99.3 & 93.7 & $51.3 \mathrm{bc}$ & $33.3 \mathrm{c}$ \\
PVS3 240 min & 98.2 & 98.1 & $63.3 \mathrm{~b}$ & $56.8 \mathrm{bc}$ \\
PVS3 360 min & 95.7 & 97.7 & $89.5 \mathrm{a}$ & $87.5 \mathrm{a}$ \\
\hline
\end{tabular}

z; Mean separation within columns by Duncan's multiple range test at $5 \%$ level 
Table 5. Survival and regeneration rates of the shoot tips of the five lily accessions cryopreserved using droplet-vitrification.

\begin{tabular}{cllcc}
\hline \hline Accession no. & Scientific name & Accession name & Survival rate (\%) & Regeneration rate (\%) \\
\hline GBL0089 & Lilium hybrid & Carmina & $89.5 \pm 4.43^{\text {z) }}$ & $87.5 \pm 5.89$ \\
GBL0099 & Lilium hybrid & Crystal Light & $67.9 \pm 5.05$ & $64.3 \pm 0.01$ \\
GBL0202 & Lilium callosum & Sinomartagon section & $83.3 \pm 7.86$ & $77.8 \pm 5.46$ \\
GBL0474 & Lilium hybrid & Santander & $57.7 \pm 7.36$ & $52.7 \pm 5.33$ \\
GBL0518 & Lilium hybrid & Marrero & $67.9 \pm 5.05$ & $60.7 \pm 3.15$ \\
\hline
\end{tabular}

z) Mean \pm standard deviation

retained high levels of shoot formation (>90\%). Bouman and De Klerk (1990) reported a survival of $8 \%$ of meristems of $L$. speciosum using a vitrification method, which was declared significant as it was the first trial of cryopreservation of Lilium spp. ever conducted. Vitrification refers to a physical process whereby a concentrated aqueous solution solidifies into metastable glass at sufficiently low temperatures. Highly concentrated cryoprotective solutions become so viscous that they solidify into a metastable glass at a practical cooling rate (Fahy et al. 1984). A vitrification procedure eliminates the need for controlled slow freezing and permits cells and meristems to be cryopreserved by a direct transfer to liquid nitrogen (Sakai et al. 1990, 1991). A few years after Bouman and De Klerk (1990) research, the vitrification method was successfully applied to five other lily genotypes (Matsumoto et al. 1995), resulting in the first successful cryopreservation of lily. The dropletvitrification method is based on the droplet-freezing method developed for potato (Schäfer-Menuhr et al. 1997). This method has also been successfully used for the cryopreservation of Prunus (De Boucaud et al. 2002), Carica papaya (Ashmore et al. 2001), Chrysanthemm (Halmagyi et al. 2004), and Musa (Panis et al. 2005). Chen et al (2011) reported the first successful cryopreservation of in vitro-grown apical meristems of Lilium by a dropletvitrification method. The highest regeneration rate was $67.6 \%$, which is much higher than the result of Bouman and De Klerk (1990) suggesting that droplet-vitrification is more efficient than vitrification as data on survival and regeneration rates of certain lily cultivars suggest.

In this study, regeneration rate (87.5\%) was higher than that reported by Chen et al (2011). In a similar study, droplet-vitrification method was reported to improve the recovery rate of Musa shoot tips compared to cryovial- vitrification (Panis et al. 2005). Survival and shoot formation rates of the five accessions of Lilium spp. studied here were compared using droplet-vitrification (Table 5) where Lilium hybrid Carmina, exhibited the highest survival $(89.5 \%)$ and regeneration rates $(87.5 \%)$. Moreover, we analyzed several factors affecting survival and regeneration to provide the foundation for the long-term cryopreservation of Lilium spp. shoot tips. We consider the droplet-vitrification method an optimum means of shoot tip or meristem cryopreservation for additional plant species because of the higher cooling rate promoted by this method. Further research is required using cytological and molecular analyses to confirm the morphological and genetic stability of regenerated plantlets produced by this type of germplasm preservation.

\section{ACKNOWLEDGEMENT}

This study was carried out with the support of Research Program for Agricultural Science \& Technology Development (Project No. PJ009369), National Academy of Agricultural Science, Rural Development Administration, Republic of Korea.

\section{REFERENCES}

Ashmore S, Azimi M and Drew RA. 2001. Cryopreservation trials in Carica papaya. Acta Hort. 560: 117-120.

Benson EE, Wilkinson M, Todd A, Ekuere U and Lyon J. 1996. Developmental competence and ploidy stability in plants regenerated from cryopreserved potato shoot tips. CryoLetters 17:119-128. 
Bouman H, De and Klerk GJ. 1990. Cryopreservation of lily meristems. ISHS Acta Horticulturae 266:331-337.

Bouman H, Tiekstra A, Petutschnig E, Homan M and Schreurs R. 2003. Cryopreservation of Lilium species and cultivars. Acta Horti. 612:147-154.

Chen H, Chen XL, Chen LQ and Lu XX. 2007. Cryopreservation of shoot tips from in vitro plants of our flower of lily (Lilium L.) by vitrification method. Journal of Plant Genetic Resources 2:170-173.

Chen XL, Li JH, Xin X, Zhang ZE, Xin PP and Lu XX. 2011. Cryopreservation of in vitro-grown apical meristems of Lilium by droplet-vitrification. South African Journal of Botany 77:397-403.

De Boucaud MT, Brison M, Helliot B and Herve-Paulus V. 2002. Cryopreservation of Prunus In: Towill LE and Bajai YPS (eds) Biotechnology in Agriculture and Forestry 50. Cryopreservation of Plant Germplasm II. Spriger, Berlin-Heidelberg, pp.287-311.

Fahy GM, MacFarlene DR, Angell CA and Meryman HT. 1984. Vitrification as an approach to cryopreservation. Cryobiology 21:407-426.

Halmagyi A, Fischer-Kluver G, Mix-Wagner G and Schumacher M. 2004. Cryopreservation of Chrysanthemum morifolium (Dendranthema grandiflora Ramat.) using different approaches. Plant Cell Rep. 22:371-375.

Hirai D, Shirai K, Shirai S and Sakai A. 1998. Cryopreservation of in vitro-grown meristems of strawberry by encapsulation vitrification. Euphytica 101:109-115.

Kaviani B, Safari-Motlagh MR, Padasht-Dehkaei MN, Darabi AH and Rafizadeh A. 2008. Cryopreservation of lily germplasm by encapsulation-dehydration. International Journal of Botany 4:491-493.

Kim HH, Yoon JW, Park YE, Cho EG, Sohn JK, Kim TS and Engelmann F. 2006. Cryopreservation of potato cultivated varieties and wild species. CryoLetters 27:223-234

Lee, Y.N. 2002. New flora of Korea. Kyohaksa, Seoul, Korea, pp.1165-1169.

Matsumoto T, Sakai A and Yamada K. 1994. Cryopreservation of in vitro-grown apical meristems of wasabi (Wasabi japonica) by vitrification and subsequent high plant regeneration. Plant Cell Rep. 13:442-446.

Matsumoto T, Sakai A and Yamada K. 1995. Cryopreservation of in vitro-grown apical meristems of lily by vitrification. Plant Cell, Tissue and Organ Culture. 41:237-241.

Panis B, Piette B and Swennen R. 2005. Droplet-vitrification of apical meristems: a cryopreservation protocol applicable to all Musaceae. Plant Sci. 168:45-55.

Rall WF and Fahy GM. 1985. Cryopreservation of mouse embryo at $-196^{\circ} \mathrm{C}$ by vitrification. Nature 313:573-575.

Sakai A, Kobayashi S and Oiyama I. 1990. Cryopreservation of nucellar cells of navel orange by vitrification. Plant Cell Rep. 9:30-33.

Sakai A, Kobayashi S and Oiyama I. 1991. Survival by vitrification of nucellar cells of navel orange cooled to $-196^{\circ} \mathrm{C}$. J. Plant Physiol. 137:465-470.

Schäfer-Menuhr A, Martin Schumacher H and Mix-Wagner G. 1997. Cryopreservation of potato cultivars: design of a mothod for routine application in genebanks. Acta Horti. 447:477-482.

Tahtamouni RW and Shibli RA. 1999. Preservation at low temperature and cryopreservation in wild pear (Pyrus syriaca). Advanced in Horticultural Science 13:156-160.

Takagi H. 2000. Recent development in cryopreservation of shoot apices of tropical species. In: Engelmann F, Takagi $\mathrm{H}$ (eds). Cryopreservation of tropical plant germplasm. Current Research Progress and Application. IPGRI, Rome, Italy, pp.178-193.

Volk GM, ManessN and Rotindo K. 2004. Cryopreservation of garlic (Allium sativum L.) using plant vitrification solution 2. CryoLetters 15:219-226.

Yoon JW, Kim HH, Ko HH, Hwang HS, Hong ES, Cho EG and Engelmann F. 2006. Cryopreservation of cultivated and wild potato varieties by droplet-vitrification : effect of subculture of mother-plants and preculture of shoot tips. CryoLetters 27:211-222.

Zhang YQ, Li XX, Ma Q, Wang HP and Shen E. 2004. Preliminary study on vitrification cryopreservation technology of edible lily germplasm. China vegetables 4:11-13. 